\title{
IN THE EYE OF THE BEHOLDER: MOTHERS' PERCEPTIONS OF POOR NEIGHBORHOODS AS PLACES TO RAISE CHILDREN
}

\author{
Trayci Dahl, Rosario Ceballo, and Marisela Huerta \\ University of Michigan
}

This study explores how mothers facing similar neighborhood conditions evaluate their neighborhoods as places to raise children. The authors relied upon a triangulation of methods, using both quantitative and qualitative methodologies, with a sample of 91 low-income mothers. Content analysis of qualitative interviews revealed that mothers often hold divergent views about the quality of the same or similar neighborhoods. Mothers' overall neighborhood perceptions were influenced by several specific indicators, including social interaction, collective efficacy, fear of crime, personal victimization, and neighborhood incivilities. Moreover, mothers' subjective neighborhood perceptions were related to their parenting strategies. This study thus underscores the importance of not solely relying on "objective" neighborhood criteria such as census data, but of also attending to residents' subjective perceptions of their own neighborhoods. (C) 2010 Wiley Periodicals, Inc.

As poverty and violent crime permeates the United States, families with few financial resources often find themselves living in neighborhoods where they are surrounded by extraordinary challenges to their well-being. Mothers who raise children in impoverished, high-risk neighborhoods face a multitude of unique obstacles that mothers who live in wealthier and safer neighborhoods do not have to contend with

\footnotetext{
Trayci Dahl is now in private practice with Orange County Forensics, Inc. Marisela Huerta is now with the Institute for Juvenile Research at the University of Illinois at Chicago.

We wish to thank all of the mothers who made time to talk with us and participate in this study. We are also appreciative of the assistance provided by many dedicated and talented University of Michigan graduate and undergraduate students. Funding for this study was provided by the Department of Psychology and the Center for Human Growth and Development at the University of Michigan.

Correspondence to: Rosario Ceballo, University of Michigan, Department of Psychology, 530 Church Street, Ann Arbor, MI 48109. E-mail: rosarioc@umich.edu
} 
(Furstenberg, 1993). Poor, inner-city neighborhoods are characterized by high unemployment rates, criminal activity, single-parent households, and sparse or deteriorating institutional resources such as schools, libraries, and parks (McLoyd, 1998). It is not surprising, therefore, that neighborhood adversity affects many aspects of family functioning and child development, including parents' approaches to parenting (Roosa, Jones, Tein, \& Cree, 2003; Simons, Johnson, Beaman, Conger, \& Whitbeck, 1996).

Subjective neighborhood assessments are likely to play an important role in determining how neighborhoods exert an influence on children and families (Silk, Sessa, Morris, Steinberg, \& Avenevoli, 2004). Yet we know relatively little about how poor mothers subjectively evaluate and perceive their neighborhoods. Many researchers have focused on "objective" neighborhood indicators, such as censuslevel variables (e.g., percentage of single-parent families, employed adults, etc.; Brody et al., 2001; Chase-Lansdale \& Gordon, 1996; Duncan \& Aber, 1997; Sampson, Raudenbush, \& Earls, 1997). Remarkably, participants' individual experiences and subjective perceptions remain absent from most research models. Hence, our study highlights this underexplored area of neighborhood influences by focusing on mothers' own subjective appraisals of their neighborhoods, thereby adding a distinct and individually subjective frame of reference to neighborhood research.

Our research approach is in keeping with the transactional model proposed by Roosa and colleagues (2003) to explain neighborhood influences. Their heuristic model incorporates individual experiences and perceptions of neighborhoods to explain differences in outcomes. According to their model, the characteristics of a neighborhood stimulate unique experiences that, in turn, result in family- and childlevel processes that ultimately influence child outcomes. More specifically, we focus on the subsection of their model that shows relations between neighborhood processes (e.g., collective efficacy) and subjective perceptions of neighborhoods, as well as between those subjective perceptions of neighborhoods and family processes (e.g., parental management strategies). We are particularly interested in one aspect of neighborhood perceptions, mothers' appraisals of their neighborhoods as places to raise children. As such, understanding how mothers perceive their neighborhoods can advance our understanding of parenting decisions and behavior. Our study relies on a mixed method approach to explore the following research questions: (a) How do mothers facing similar neighborhood conditions evaluate the quality of their neighborhoods as places to raise children? (b) Do subjective neighborhood evaluations map on to specific neighborhood quality indicators? (c) Are mothers' subjective neighborhood assessments associated with parenting strategies?

\section{SPECIFIC INDICATORS OF NEIGHBORHOOD QUALITY}

A multitude of factors are likely to influence mothers' neighborhood perceptions. All mothers who live in poor neighborhoods do not uniformly condemn their neighborhoods. Although researchers often focus on a single indicator of neighborhood quality, the theoretical rationale behind the choice of which indicator to investigate is frequently left unexplained, and the relative importance of different neighborhood indicators is rarely investigated. Consequently, we know little about how specific neighborhood criteria factor into overall subjective appraisals of neighborhood conditions. Here we explore how several neighborhood indicators are associated with 
mothers' evaluations of their neighborhoods as places to raise their children. Specifically, the influence of five characteristics are examined: social interaction, collective efficacy, fear of crime, personal victimization, and neighborhood incivility, defined as the general appearance of order and disorder as indicated by such things as litter, graffiti, abandoned buildings, and disorderly teens.

The extent to which mothers participate in social interactions and relationships with their neighbors will undoubtedly impact mothers' neighborhood appraisals. For example, neighborhood attachment and social isolation are important predictors of an individual's perception of neighborhood safety (Delisi \& Regoli, 2000). Baba and Austin (1989) found that perceptions about the physical environment and about neighbors were the strongest predictors of residents' perceptions of neighborhood safety. Sampson, Raudenbush, and Earls (1997) measured collective efficacy, residents' perceptions of social cohesion, and neighbors' willingness to intervene on behalf of others. In their sample of over 8,000 adults, collective efficacy was closely linked to objective indicators of crime and violence. In addition to criminal activity, Duncan, Duncan, Okut, Strycker, and Hix-Small (2003) reported that family structure was also predictive of collective efficacy such that single-parent families had lower perceptions of collective efficacy compared to two-parent families. Further, the presence of social cohesion may serve to buffer and protect both children and adults from physical and psychological harm (Chase-Lansdale \& Gordon, 1996; Pettit, Bates, Dodge, \& Meece, 1999).

Concerns and behavior associated with fear of crime are disproportionately carried by poor women in our society. Even though men are more likely to be victimized by all types of crime, except for rape, women fear crime more than men (Riger, LeBailly, \& Gordon, 1981). Further, women who have fewer neighborhood bonds and less social interaction within their neighborhoods are more afraid of crime than women who have more neighborhood connections. Because high rates of crime and victimization are all too common in poverty-stricken communities, it is not surprising that parental perceptions of neighborhood danger have been linked to children's distress (Shumow, Vandell, \& Posner, 1998). Relatedly, signs of social disorder or incivility impact residents' neighborhood perceptions. As individuals perceive greater incivility, they tend to become more aware and fearful of crime (LeGrange, Ferraro, \& Supancic, 1992; Lewis \& Maxfield, 1980).

\section{PARENTING IN POOR, DANGEROUS NEIGHBORHOODS}

Neighborhood characteristics may prompt various adaptations in parenting style - both positive and negative (Pinderhughes, Nix, Foster, Jones, \& the Conduct Problems Prevention Research Group, 2001). In poor neighborhoods, children may benefit from a parenting style that may be considered excessively strict in safer neighborhoods (Baldwin, Baldwin, \& Cole, 1990; Leventhal \& Brooks-Gunn, 2000). With 120 African American adolescents, Gonzales, Cauce, Friedman, and Mason (1996) found that greater maternal restrictiveness was associated with children's poorer academic achievement, while permissiveness was related to higher grades in low risk neighborhoods. In high-risk neighborhoods, however, the findings were reversed, and maternal restrictiveness was related to higher grades. In poor, urban neighborhoods parents must often exercise more control than seems appropriate in middle class neighborhoods. O'Neill, Parke, and McDowell (2001) found that mothers' subjective neighborhood perceptions predicted parental regulation strategies. In 
neighborhood areas that mothers perceived to be problem-ridden, mothers limited their children's activities, and children reported greater parental supervision.

Qualitative studies have revealed several parenting strategies that have proven successful in impoverished neighborhoods (Burton \& Jarrett, 2000; Furstenberg, 1993; Jarrett, 1997; Letiecq \& Koblinsky, 2004). One strategy relies on strict monitoring of children; this translates into constant chaperoning, vigilant supervision, and the restriction of outdoor activities. Another strategy consists of physical and social withdrawal from the neighborhood in actual or symbolic ways. For example, social distance between a family and neighbors may be created by restricting interactions with neighbors and by highlighting ways in which a family is different from their neighbors.

\section{THE CURRENT STUDY}

In exploring mothers' neighborhood perceptions, we relied upon a triangulation of methods using both quantitative surveys and qualitative interview methods. Feminist research has a long tradition of emphasizing the importance of learning about women's perceptions from their own experiences and in their own words (Collins, 2000). Qualitative methods are particularly well-suited for understanding rich nuances and complexities in women's experiences because they do not limit participants to preestablished categories or scales. We utilized in-depth, semistructured interviews to better understand how poor mothers thought about, understood, and made judgments about their neighborhoods in relation to their parenting roles. A fundamental premise for our study was that mothers may have different appraisals of the same neighborhood and that these evaluations might be positive ones. Patricia Hill Collins (2000) underscores the relative benefits and drawbacks of researchers who have "insider" versus "outsider" status relative to the populations they study. Despite the fact that some of the authors can claim working-class backgrounds, as outsiders to the neighborhoods where we worked, we would have had difficulty identifying positive neighborhood attributes. Consequently, our qualitative interview began by asking mothers, "Do you feel that your neighborhood has a good effect on your child? And, if yes, how?" followed by, "Do you feel that your neighborhood has a harmful effect on your child? And, if yes, how?"

It is important to note that there is no single, commonly accepted definition of what constitutes a "neighborhood." Census tracts, for example, are statistically imposed, artificial boundaries that may or may not correspond to residents' perceptions of their neighborhoods (Roosa et al., 2003). In the current study, mothers defined their neighborhoods in whatever manner they chose. Whereas some mothers said their neighborhood consisted of several city blocks, others said their neighborhood included the one square block on which they lived.

\section{METHOD}

\section{Participants}

Our sample was comprised of 91 mothers residing in economically disadvantaged, high-risk neighborhoods in Detroit, Michigan. In 2005, the rate of violent crimes 
Table 1. Demographic Characteristics of Mothers $(N=91)$

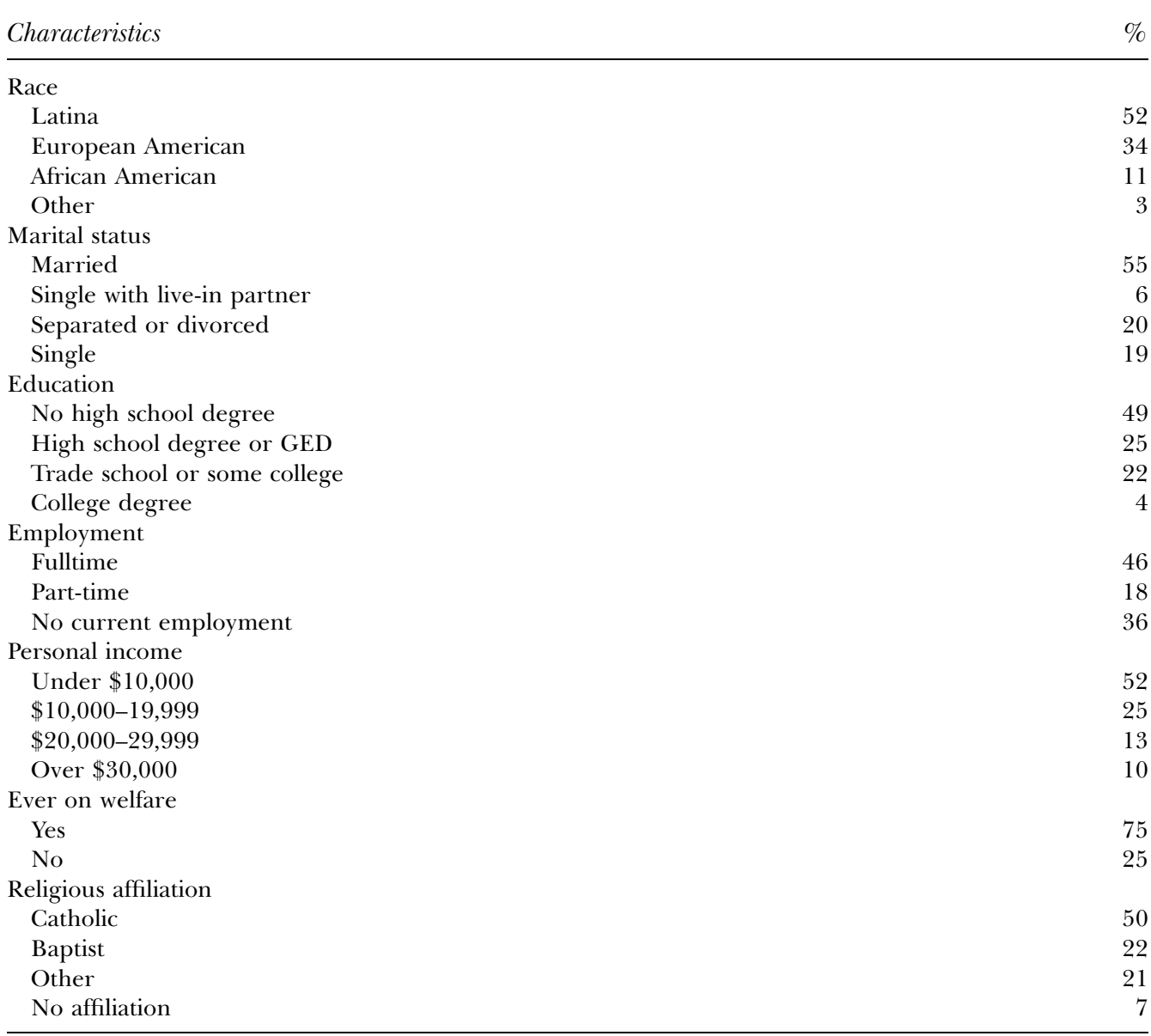

Note: GED = general equivalency diploma.

(murder, rape, robbery, and aggravated assault) reported totaled 2,358 per 100,000 people in Detroit, which is much higher than the national average of 469 violent crimes per 100,000 people (Federal Bureau of Investigation, 2008). The families in our sample resided in two census tracts with $28 \%$ and $27 \%$ of families living below the poverty line, compared to $9 \%$ of U.S. families living below poverty (U.S. Census Bureau, 2000).

Demographic information for our sample of mothers and legal guardians (10\%) is presented in Table 1. The mothers identified themselves as a multiethnic group, with 47 women identifying as Latina (primarily Mexican American), 31 European American, 10 African American, and 3 racially unidentified mothers. The mean age of the mothers was 35 years old $(S D=6.69)$, and they had an average of 3.3 children $(S D=1.41)$. These mothers represent a highly impoverished group with half of the mothers reporting annual personal incomes under $\$ 10,000,75 \%$ of the mothers reporting that they relied on government assistance at some time, and nearly half of the mothers reporting that they did not have a high school degree. 


\section{Procedures}

Parental recruitment and consent letters were sent home with all children enrolled in the fourth and fifth grade at two elementary schools, yielding response rates of $58 \%$ in one school and $77 \%$ in the other school. Mothers of participating children were subsequently contacted, either by telephone or in person, to schedule interviews. Of 163 children who participated, $70 \%$ of their mothers were recruited and interviewed by graduate and undergraduate research assistants. The interviewing team included Spanish-speaking Latina, European American, African American, and Native American women who interviewed the mothers in their homes or local fast food restaurants. The mother interview consisted of two parts, a semistructured, open-ended interview and several quantitative measures. In total, the interview took approximately 2.5 hours, and participating mothers received $\$ 50$ for their time.

All mothers were given the option of participating in either English or Spanish. All of our study materials were translated and back-translated by bilingual, native Spanishspeakers. Bilingual graduate students worked with participants who preferred to complete the interview in Spanish. On the measures utilized in this study, there were no significant differences in mean levels between mothers who participated in English versus Spanish.

\section{Qualitative Interview Coding}

The qualitative interview assessed maternal perceptions of their neighborhoods and neighborhood influences on their children and their parenting strategies. A standard set of 10 questions was asked of every mother. However, interviewers were instructed to ask as many follow-up questions as possible to elicit specific examples and a greater understanding of mothers' experiences and view points. This portion of the interview was tape recorded with the participant's permission and later transcribed verbatim.

The qualitative interview transcripts were coded to categorize mothers' assessments of their neighborhoods as places to raise children. Neighborhood perceptions were grouped into four categories based on careful readings of a group of randomly selected interview transcripts and the desire to identify nonoverlapping attitudes about neighborhoods.

Consistently negative. This group included mothers who believed that their neighborhood had a harmful effect on their children and listed many examples of the dangers in their neighborhoods. Mothers who simply listed neighborhood dangers were also placed in this group.

Consistently positive. Mothers in this group believed that their neighborhood had a good effect on their children. Additionally, they did not list any neighborhood dangers during the entire interview and denied any negative neighborhood effects on their children. To ensure that these mothers were not simply providing socially desirable answers, mothers were only coded into this category if they provided concrete examples supporting their positive perceptions.

Inconsistent. This group of mothers stated that their neighborhood had a positive effect on their children, but subsequently listed serious neighborhood dangers. Alternatively, these mothers may have stated that their neighborhood did not have a harmful effect 
on their children but still went on to recount serious neighborhood problems for children.

Both positive and negative. These mothers saw their neighborhoods as having both positive and negative effects on their children and admitted the presence of dangers in the neighborhood. They described helpful as well as harmful neighborhood characteristics in a balanced viewpoint.

A coding manual was constructed with specific instructions and examples for the coding of the mother interviews. The unit of analysis was an entire interview transcript. Six undergraduate students and one graduate student were trained and given practice interviews (from another study) to code in order to establish initial accuracy. Discussions followed each round of practice interview coding to establish clear criteria for the application of codes. Accuracy for the practice interviews was established by comparing the coders' ratings with the first author's codes and deemed adequate when each coder's agreement reached $80 \%$.

After the training and practice interviews, undergraduate student coders were paired into teams and each team initially coded one third of the interviews, with each interview being coded independently by both members of a team. Percentage agreement was used as the index of intercoder reliability. Reliability for each interview was calculated using the formula: percentage agreement $=$ number of agreements/ (number of agreements + number of disagreements) $\times 100$ (Miles \& Huberman, 1994; Neuendorf, 2002). Nine interviews with intercoder reliability falling below $80 \%$, after coding by two different teams, were excluded.

\section{Measures}

Social interaction. Neighborhood social interaction was measured with an 18-item scale adapted from the Neighborhood Social Cohesion Scale (Riger et al., 1981), designed to assess the degree of social interaction with neighbors. Respondents were asked to rate the frequency with which they typically engage in activities such as going out for entertainment with a neighbor or asking a neighbor for advice. Responses were scored on a 5-point Likert scale ranging from (1) never social to (5) very often social with higher scores indicating greater social interaction within the neighborhood. Cronbach's $\alpha$ for this scale was .91 .

Collective efficacy. Perceptions of collective efficacy were assessed with a 10-item measure (Sampson et al., 1997). This scale assessed the degree to which adults are willing to intervene and act on behalf of the common good. Mothers responded to questions on a 5-point Likert scale, indicating level of agreement. Appropriate items were reverse scored so that higher scores on this measure represent higher perceptions of collective efficacy. An example question was, "How strongly do you agree that people around here are willing to help their neighbors?" The Cronbach's $\alpha$ for this scale was .87 .

Fear of crime. Mothers' fear of crime within their neighborhood was assessed with two questions: "How safe do you feel being out alone in your neighborhood at night?" and "How safe do you feel being out alone in your neighborhood during the day?" (Rohe $\&$ Burby, 1988). Responses were scored on a 4-point Likert scale ranging from (1) very safe to (4) very unsafe. The Cronbach's $\alpha$ was .69. We considered this alpha acceptable 
because this scale consisted of only two items and alpha values tend to be lower with fewer items. Moreover, the amount of fear a respondent feels during the day may indeed be different than the amount of fear the same respondent experiences at night.

Personal victimization. The Survey of Exposure to Community Violence (Richters \& Martinez, 1993), a scale intended to measure children's exposure to violence, was modified to assess the frequency of mothers' lifetime exposure to different types of violence. A personal victimization subscale $(\alpha=.76)$, consisting of 11 items, was created by adding the number of incidents mothers reported having experienced, such as being beaten or mugged and attacked or stabbed with a knife. Higher scores indicated more experiences of personal victimization.

Neighborhood incivility. The Neighborhood Incivilities Scale (Lewis \& Maxfield, 1980) was designed to measure perceptions of offensive neighborhood appearances such as vandalism, unsupervised teenagers, and gang activity. Responses to the nine items were scored on a 3-point Likert scale ranging from (1) not a problem at all to (3) big problem. Higher scores reflected greater incivilities, and the Cronbach's $\alpha$ was .87 for our sample.

Restrictive parenting. A scale of restrictive parenting was constructed and coded from the qualitative mother interviews. The procedure followed for training and coding this construct mirrored those used for the coding of neighborhood assessments. Mothers were given one point for the presence of strict parental monitoring defined as strict supervision and intensive monitoring of children's activities, whereabouts, and social networks. Another point was given to mothers who utilized physical or social withdrawal from the community. These activities included limiting contact with "outsiders," confining children to the home as much as possible, and erecting symbolic boundaries that set their family apart from others. Scores ranged from 0 to 2, with higher scores representing a reliance on strict monitoring and withdrawal strategies.

\section{RESULTS}

\section{Qualitative Findings}

In addressing our first research question (How do mothers facing similar neighborhood conditions evaluate their neighborhoods as places to raise children?), we found that mothers in similar neighborhoods often hold contrasting and divergent views about the quality of their neighborhoods. In other words, mothers in the "same" neighborhood did not necessarily evaluate their neighborhoods in similar ways. Pseudonyms will be used, instead of mothers' real names, to protect the participants' confidentiality. In this section, we will provide descriptive profiles of mothers' assessments of their neighborhoods by four categories (consistently negative, consistently positive, inconsistent, and both positive and negative).

There were 33 mothers in the consistently negative group who described their neighborhoods as dangerous residential areas with high crime rates, frequent gunfire, disorderly teens, drug dealers, and prostitutes. Almost half of these mothers also spoke about their children's awareness of the violence and dangers within their neighborhoods. Some of these mothers were concerned that their children were growing up too fast 
because of the many negative neighborhood influences. Gloria remarked, "Yeah, she (her daughter) sees it (drugs), she knows. That's the sad part. (Laughs) That's the sad part. I got a 9-year-old and an 11-year-old that know the facts of life already, and had no chance to grow up slowly, had to be taught it right away, you know." Evident among these mothers was a feeling of helplessness, a sense of being unable to protect their children from the violence around them.

Many of these mothers described a profound sense of fear permeating their family's lives. Linda described her neighborhood as being akin to a battle. Another mother, Mercedes, didn't feel safe in her own home and explained, "Thank God nothing has ever happened. But, you know, the only thing I fear is that when their bullets are flying, you really don't know where they're going to land. So, several times we've been on the floor sleeping." In sum, these women perceived many incivilities, felt that their children witnessed crime and violence, and recounted many instances in which they felt afraid for their safety. Their neighborhood assessments were in direct contrast to those of the consistently positive group of mothers.

Interestingly, some of the women in the consistently positive group lived on the same blocks as the women in the consistently negative group. Regardless of that fact, the 16 women in this group had completely different perceptions of their neighborhoods. These mothers described positive ways in which their neighborhoods influenced their children. Christina believed that her neighborhood had a good effect on her children because of, "the fact that you hardly hear that there's like gangs around here. This little part of my neighborhood, I actually grown up here. You've never heard any like, anybody coming into our houses, stealing, and all these things. I've never had that. No." These mothers' views were in stark contrast to mothers in the consistently negative group who felt that their children were exposed to violence, drugs, and prostitution. Sharon stated that her child "can go outside, because he doesn't have to worry that they're doing bad things in the surrounding area and such. You don't see anything bad in the part of the neighborhood where we live."

These mothers firmly believed that their neighborhoods were good places to live and raise children. Common factors supporting their positive appraisals included limited gang exposure, frequent police patrol, little experience with personal victimization, and neighborhood resources for children. In Kelly's opinion, the neighborhood had a positive effect on her children because she was able to engage them in positive activities, such as sports and neighborhood church groups. Melinda also identified helpful neighborhood resources, specifically a local recreation center where her children received help with homework.

The inconsistent group was comprised of 20 mothers who described their neighborhoods as having an overall positive impact on their children, yet also provided detailed descriptions of the presence of violence and other serious neighborhood dangers during their interviews. The mothers in this group denied that their neighborhoods had a negative effect on their children. Similar to the mothers in the consistently negative group, about half of the mothers in the inconsistent group stated that their children were aware of community violence and crime. For example, Linda explained, "My son understands and so does my daughter. My daughter, she's five, she understands what a crack house is." Nonetheless, these mothers defended their neighborhoods as good places to live and raise children. A few of the mothers in this group valued their neighborhoods because they appreciated having their children grow up in a culturally rich and diverse environment. When asked if she thought that her neighborhood had a good effect on her children, Rosa 
replied, "Yes, I do. Well, basically, they're being raised in a neighborhood with so many different cultures. They're able to learn about different people. It's not just like a specific race or color or anything like that. It's a complete mixture. So they're learning really to adapt to everything around them."

The 22 mothers in the both positive and negative group believed that their neighborhoods had the potential to harm as well as benefit their children. A few of the mothers in this group also included cultural diversity as a positive neighborhood characteristic. Janet referenced the cultural richness in the neighborhood by explaining, "Well, in some cases I do believe it (the neighborhood) has a good effect on my children 'cause there's a lot of different resources and community projects that go on and lots of things that can help my kids. Like when they have the Cinco de Mayo parade ..." For Alicia, the positive aspects of her neighborhood were: "I have good neighbors. [My daughter] gets along well with all the kids, all the neighbor's kids." Then she added some negatives, "Sometimes what I don't like is that there's a lot of, some families are always drinking, using drugs outside their house in front of the kids." Perhaps for Alicia the neighborly support she received compensated for raising children in an environment that she described as permeated by drugs. In another example, Janet's perceptions of the dangers within her neighborhood included "the number of guns that are in the neighborhood. And you hear the gun shots and you gotta worry." But, on the positive side, she noted that, "there's really no big gang fights in my neighborhood anymore. Since, you know, [the mayor's] come in, and he has cleaned up a lot of the gang activity. I mean, it's a lot better than it was 5 years ago, a lot better than it was 5 years ago. I mean, I was scared to walk to the store 5 years ago."

These women often seemed surprisingly impervious to, yet quite aware of the extremely high rates of violence surrounding them. Anecdotally, emotional numbing and apathy have been associated with chronic exposure to high rates of community violence. Some mothers in this group described their children as numb to the effects of violence, much like they described themselves. For instance, Julie explained that her children experienced, "a lot of racial slurs, gang signs, things like that. They already know what drugs are. And at 9, under 10 years old, they're aware of it. They're not afraid of it. They used to be when they were small, but given that, you know, growing up with it, you get kind of numb to it."

\section{Quantitative Findings}

First, we conducted one-way ANOVAs and cross-tabulations to determine if there were any significant associations between mothers' demographic characteristics and the four qualitatively coded neighborhood groups just described. We found no significant associations between the four neighborhood assessment categories and a host of demographic characteristics, including mother's age, race, marital status, number of children, annual household income, length of time living in the neighborhood, length of time living in the United States, stressful life events in the past year, single-parent versus two-parent household, and regular attendance at religious services. Moreover, mothers' depression scores did not vary by neighborhood groups so that maternal neighborhood assessments were not simply reflecting depressive versus more optimistic outlooks about the world around them.

Next, we explored our second research question: In what ways do mothers' subjective neighborhood evaluations map on to specific neighborhood quality indicators? A multivariate analysis of variance (MANOVA) was performed to 
Table 2. Multivariate and Univariate Analyses of Variance for Neighborhood Variables

\begin{tabular}{|c|c|c|c|c|c|c|c|c|c|c|c|}
\hline \multirow[b]{3}{*}{ Variable } & \multicolumn{11}{|c|}{ Univariate } \\
\hline & \multicolumn{2}{|c|}{ Multivariate } & \multicolumn{2}{|c|}{ Negative } & \multicolumn{2}{|c|}{ Positive } & \multicolumn{2}{|c|}{ Inconsistent } & \multicolumn{2}{|c|}{ Both } & \multirow[b]{2}{*}{$F^{\mathrm{b}}$} \\
\hline & $\eta^{2}$ & $F^{\mathrm{a}}$ & $M$ & $S D$ & $M$ & $S D$ & $M$ & $S D$ & $M$ & $S D$ & \\
\hline & 0.22 & $4.72^{* * *}$ & & & & & & & & & \\
\hline Social interaction & 0.09 & & $2.34^{\mathrm{a}}$ & $(0.92)$ & 2.79 & $(0.90)$ & $3.08^{\mathrm{b}}$ & $(0.94)$ & 2.56 & $(0.90)$ & $2.87^{*}$ \\
\hline Collective efficacy & 0.34 & & $26.42^{\mathrm{a}}$ & $(8.29)$ & $39.50^{\mathrm{b}}$ & $(4.70)$ & $37.00^{\mathrm{b}}$ & $(6.10)$ & $33.82^{\mathrm{b}}$ & $(8.36)$ & $15.01^{* * *}$ \\
\hline Fear of crime & 0.20 & & $2.76^{\mathrm{a}}$ & $(0.74)$ & $2.00^{\mathrm{b}}$ & $(0.66)$ & $1.98^{\mathrm{b}, \mathrm{c}}$ & $(0.68)$ & $2.59^{\mathrm{d}}$ & $(0.72)$ & $7.43^{* * *}$ \\
\hline Victimization & 0.13 & & $3.03^{\mathrm{a}}$ & $(2.08)$ & $1.19^{\mathrm{b}, \mathrm{c}}$ & $(0.54)$ & 2.20 & $(1.36)$ & $3.00^{\mathrm{d}}$ & $(2.43)$ & $4.23^{* *}$ \\
\hline Incivility & 0.25 & & $2.35^{\mathrm{a}}$ & $(0.40)$ & $1.64^{\mathrm{b}, \mathrm{c}}$ & $(0.43)$ & $2.02^{\mathrm{b}}$ & $(0.42)$ & $2.12^{\mathrm{d}}$ & $(0.52)$ & $9.52^{* * *}$ \\
\hline
\end{tabular}

Note: Subscripts of a and b, or c and d denote means that differ significantly between groups. $F$ ratios are Wilks's approximation of $F$ s. ${ }^{\mathrm{a}}$ Multivariate $d f=15,230 .{ }^{\mathrm{b}}$ Univariate $d f=3,87$.

${ }^{*} p \leq .05 ;{ }^{* *} p \leq .01 ; * * * \leq .001$

determine whether significant differences existed between the four groups on measures of social interaction, collective efficacy, fear of crime, personal victimization, or neighborhood incivility. The results of the MANOVA are shown in Table 2. Significant multivariate effects were obtained, Wilks's lambda $=.22, F(15,230)=4.72$, $p<.001$. Analysis of the univariate effects for social interaction, $F(3,87)=2.87, p<.05$, collective efficacy, $F(3,87)=15.01, p<.001$, fear of crime, $F(3,87)=7.43, p<.001$, mother's own personal victimization, $F(3,87)=4.23, p<.01$, and neighborhood incivility, $F(3,87)=9.52, p<.001$, all demonstrated a significant contribution to mothers' assessments of their neighborhoods. Tests of estimates of effect sizes revealed that collective efficacy $\left(\eta^{2}=.34\right)$ had the greatest effect on neighborhood evaluations, followed by neighborhood incivilities $\left(\eta^{2}=.25\right)$, fear of crime $\left(\eta^{2}=.20\right)$, personal victimization $\left(\eta^{2}=.13\right)$ and then finally social interaction $\left(\eta^{2}=.09\right)$.

Bonferroni tests were conducted to investigate how the four patterns of neighborhood assessment differed from each other with regard to social interaction, collective efficacy, fear of crime, personal victimization, and incivility. Mothers in the consistently negative group reported the least amount of social interaction of any of the groups $(M=2.34, S D=.92)$, and they reported significantly less social interaction than mothers in the inconsistent group $(M=3.08, S D=.94, p<.05)$. Similarly, mothers in the consistently negative group endorsed the lowest levels of collective efficacy $(M=26.42, S D=8.29)$ and reported significantly lower levels of collective efficacy compared to mothers in the other three groups, consistently positive $(M=39.50$, $S D=4.70, p<.001)$, inconsistent $(M=37.00, S D=6.10, p<.001)$, and the both positive and negative group $(M=33.82, S D=8.36, p<.01)$.

Not surprisingly, mothers in the consistently negative group reported the highest rates of fear of crime $(M=2.76, S D=.74)$ compared to mothers in the other groups. The consistently negative mothers were significantly more fearful than either the consistently positive mothers $(M=2.00, S D=.66, p<.01)$ or the inconsistent groups of mothers $(M=1.98, S D=.68, p<.01)$. The group of mothers with inconsistent neighborhood evaluations was significantly less fearful than mothers in the both positive and negative group $(M=2.59, S D=.72, p<.05)$.

The consistently negative group of mothers had significantly more experiences with victimization $(M=3.03, S D=2.08)$ than the consistently positive group 
$(M=1.19, S D=.54, p<.01)$. Additionally the consistently positive group of mothers reported significantly fewer experiences of personal victimization than mothers in the both positive and negative group $(M=3.00, S D=2.43, p<.05)$.

Finally, the consistently negative group of mothers had the highest incivility score $(M=2.35, S D=0.4)$ when compared to the other mothers. These mothers perceived significantly more incivilities than either the consistently positive mothers $(M=1.64$, $S D=.43, p<.001)$ or the inconsistent group of mothers $(M=2.02, S D=.42, p<.05)$. The consistently positive mothers reported significantly lower incivility scores than mothers in the both positive and negative group $(M=2.12, S D=.52, p<.01)$.

Lastly, we turned to our third research question by investigating how mothers' subjective neighborhood assessments were associated with mothers' parenting strategies. Results of between-subjects ANOVA indicated that mothers' neighborhood perceptions were significantly related to parenting behavior. Specifically, there were statistically significant differences between the group mean scores on the measure of restrictive parenting, $F(3,87)=5.85, p<.001$. Mothers who rated their neighborhoods as consistently negative employed significantly more monitoring and withdrawal strategies $(M=1.42, S D=.79)$ than mothers who rated their neighborhoods as consistently positive $(M=.69, S D=.70, p<.05)$, inconsistent $(M=.70, S D=.73$, $p<.01)$, and both positive and negative $(M=.77, S D=.81, p<.05)$.

\section{DISCUSSION}

A host of statistical techniques now empower researchers to conduct geo-coding of block-level, neighborhood data, census tract data, and crime data. The range of techniques and methodological possibilities for capturing objective neighborhood variables are indeed impressive. Yet, we would be remiss to forget that our perceptions of "objective" community variables are always filtered by subjective experiences. Although statistical programs can draw inferences from averages and common trends, individuals rely on past histories, family stories, salient experiences, and personal characteristics or styles of approaching the world. Most of us readily acknowledge that "beauty is in the eye of the beholder." Perhaps, we must take care to remember that this appears to be equally true for the "beauty" and "ugliness" of our neighborhoods. "By relying solely on objective indicators of neighborhood quality, most research may have eliminated an important source of individual and family differences in responses to neighborhood conditions" (Roosa et al., 2003, p. 60). Thus, the present study underscores the importance of attending to subjective appraisals of neighborhood context and how such perceptions may shape parenting behaviors in response to surrounding environments.

In the present study, we found that mothers living under similar neighborhood conditions and even residing on the same neighborhood block, could have highly discrepant views about their neighborhoods as places to live and raise a family. In our sample, mothers spanned the spectrum from those who were entirely negative about their neighborhoods to those who were consistently positive. Mothers who cited positive neighborhood attributes referred to good neighbors, cultural diversity, a decline in crime, and neighborhood activities for children. Nonetheless, some researchers may claim that these positive evaluations incorporate a certain amount of denial. For example, one mother in the consistently positive group said, "We don't leave them [the children] by themselves because it's not good. Even though we don't 
have any dangers, it's not good to leave them by themselves." But if, in fact, there were no dangers, couldn't her children be left unsupervised? It is noteworthy, however, that a certain amount of denial and positive thinking may promote psychological benefits. Indeed, mothers in the consistently positive group may have been more adept or skilled at seeking positive neighborhood resources for their children. Alternatively, perceptions can be quite relative and mothers may have recognized certain dangers and still rated their neighborhoods as "better" than their previous living situation in another neighborhood, city, or country.

Some mothers comfortably occupied a middle ground between positive and negative evaluations and delicately interwove opposing neighborhood strengths and dangers into one cohesive perspective. In describing her neighborhood, one mother said, "the first thing you have to learn when you move into my neighborhood is how to duck [from gunfire], but I think that's about anywhere you go nowadays. I mean, it's [gunfire] there, so the fact that they [her children] know what's going on; they know how to, you know, handle things. So, you know, it depends on the predicaments they get in when they get older, whether it be a good effect or a bad effect, but I think they benefit from it, you know. They do learn survival." Hence, mothers may hold different goals for childrearing, and these may partially account for differing neighborhood assessments. For instance, some mothers may value having children acquire "street smarts" and survival skills.

Still, other mothers may refuse to allow their surrounding environment to determine outlooks and goals for their family. A mother in the inconsistent group said, "It's just a great neighborhood regardless of what other people say about the gangs and stuff. You know, it depends on the person and what you want to do and what you want to be. You know, you can live anywhere. You can live in the suburbs and still be a failure. So, it doesn't matter where you live. You know, it depends on the person." As outsiders, we tend to observe the deteriorating condition of houses and buildings, the litter and graffiti, and the multiple signs of abandonment. Accordingly, many research measures are designed to assess negative neighborhood characteristics. Research inquiries about both positive and negative neighborhood attributes are more likely to reveal neighborhood perceptions that can be highly nuanced and complex.

In forming overall neighborhood evaluations, mothers relied on a number of different and distinct neighborhood indicators, including social interaction, collective efficacy, fear of crime, personal victimization by violence, and neighborhood incivilities. All of these neighborhood factors mattered to the mothers in our study. As predicted, mothers in the consistently negative group reported the least amount of social interaction, the lowest collective efficacy ratings, the highest fear of crime rates, the greatest amount of victimization, and the highest incivility scores. In comparison, mothers with consistently positive assessments displayed an opposite pattern. Additionally, mothers in the inconsistent group and in the both positive and negative group fell somewhere in the middle of the extreme ratings. Among our sample, collective efficacy had the greatest impact on neighborhood evaluations, followed by neighborhood incivilities and fear of crime. External appearances and the extent to which mothers could rely on their neighbors to act on behalf of a "common good" were clearly important to these mothers raising young children. Interestingly, fear of crime was more important than actual experiences with victimization in formulating overall neighborhood assessments.

Mothers' neighborhood evaluations were related to parenting behavior in expected ways. Mothers who believed that their neighborhoods had a negative effect 
on their children were more likely to rely on restrictive parenting and the use of withdrawal strategies. One mother (consistently negative group) explained when she decided to use more restrictive strategies, "I used to live two blocks over and one of the gang members over there, because he [her son] would not join into their gang, banged his [her son's] head into a stop sign. So that's when I made the decision that he can't go anywhere without me or an adult." This mother experienced a sense of constant worry for her children. She explained, "I worry every day about him. I say a prayer every morning for him because you don't know what is going to happen. Even at school. . . . What happened was there was a murder, approximately 3 weeks ago, 3 weeks to a month, and a 19-year-old boy got shot. He died within a minute and a half, and it was only four houses down from me. Yes, he [her son] got scared. He got scared because he actually went down when I was not home and saw the blood in the backyard." Another mother (both positive and negative group) described the use of withdrawal strategies, "Well, I really don't let 'em out. I have them closed in. . . . even 3 years we've been here, but still, I have a hard time trusting people. I would tell them things like not to trust anybody. Even if you know them, don't trust them."

Several limitations in the present study should be noted. Given our sample of convenience and cross-sectional design, we cannot make claims about causality or the generalizability of results. Further, our modest response rates may indicate that our sample is biased by an inclusion of poor mothers who are functioning at higher levels. Poor mothers who were more greatly stressed by parenting demands may have been less likely to participate. Finally, our qualitative interview may have been more accurate with mothers who are articulate and comfortable talking to researchers, as opposed to mothers who are more reticent. Along similar lines, we were not able to match mother and interviewer pairs by race or economic backgrounds, and such differences may have influenced the responses provided by some of the mothers.

Despite these limitations, a key strength of the current study is the use of a triangulation of methods, relying on both quantitative and qualitative data for analyses. This approach provided our sample, a highly impoverished group of mothers, with the opportunity to voice and explain their experiences of parenting in high-risk neighborhoods in their own words. Our findings simultaneously underscore the importance of attending to poor individuals' subjective evaluations of their own neighborhoods while cautioning against a complete reliance on objective neighborhood criteria such as census-level variables. We found that residents of the same or similar neighborhoods can hold vastly divergent views about the quality of their communities. Identifying the many possible factors that lead residents of the same neighborhood to hold discrepant views and opinions about their neighbors and communities is an area in need of greater scholarly attention.

\section{REFERENCES}

Baba, Y., \& Austin, D. (1989). Neighborhood environmental satisfaction, victimization, and social participation as determinants of perceived neighborhood safety. Environment and Behavior, 21, 763-780.

Baldwin, A.L., Baldwin C., \& Cole, R.E. (1990). Stress-resistant families and stress-resistant children. In J. Rolf, A.S. Masten, D. Cicchetti, K.H. Nuechterlein, \& S. Weintraub (Eds.), Risk and protective factors in the development of psychopahology, (pp. 257-280). Cambridge: Cambridge University Press. 
Brody, G.H., Ge, X., Conger, R., Gibbons, F.X., Murry, V.M., Gerrard, M., et al. (2001). The influence of neighborhood disadvantage, collective socialization, and parenting on African American children's affiliation with deviant peers. Child Development, 72, 1231-1246.

Burton, L.M., \& Jarrett, R.L. (2000). In the mix, yet on the margins: The place of families in urban neighborhood and child development research. Journal of Marriage and the Family, $62,1114-1135$.

Chase-Lansdale, L., \& Gordon, R. (1996). Economic hardship and the development of five- and six-year-olds: Neighborhood and regional perspectives. Child Development, 67, 3338-3367.

Collins, P.H. (2000). Black feminist thought: Knowledge, consciousness, and the politics of empowerment. New York: Routledge.

Delisi, M., \& Regoli, B. (2000). Individual neighborhood attachment and perceptions of neighborhood safety. American Journal of Criminal Justice, 24, 181-188.

Duncan, G.J., \& Aber, J.L. (1997). Neighborhood models and measures. In J. Brooks-Gunn, G.J. Duncan, \& J.L. Aber (Eds.), Neighborhood poverty: Context and consequences for children (pp. 62-78). New York: Russell Sage Foundation.

Duncan, T.E., Duncan, S.C., Okut, H., Strycker, L.A., \& Hix-Small, H. (2003). A multilevel contextual model of neighborhood collective efficacy. American Journal of Community Psychology, 32, 245-252.

Federal Bureau of Investigation. (2008). Violent crimes. Uniform crime statistics. Retrieved March 2008, http://www.fbi.gov/

Furstenberg, F.F. (1993). How families manage risk and opportunity in dangerous neighborhoods. In W.J. Wilson (Ed.), Sociology and the public agenda (pp. 231-258). Newbury Park, CA: Sage.

Gonzales, N.A., Cauce, A.M., Friedman, R.J., \& Mason, C.A. (1996). Family, peer, and neighborhood influences on academic achievement among African-American adolescents: One year prospective effects. American Journal of Community Psychology, 24, 365-387.

Jarrett, R.L. (1997). African American family and parenting strategies in impoverished neighborhoods. Qualitative Sociology, 20, 275-288.

LeGrange, R., Ferraro, K., \& Supancic, M. (1992). Perceived risk and fear of crime: Role of social and physical incivilities. Journal of Research in Crime and Delinquency, 29, 311-334.

Letiecq, B.L., \& Koblinsky, S.A. (2004). Parenting in violent neighborhoods. Journal of Family Issues, 25(6), 715-734.

Leventhal, T., \& Brooks-Gunn, J. (2000). The neighborhoods they live in: The effects of neighborhood residence on child and adult outcomes. Psychological Bulletin, 126, 309-336.

Lewis, D.A., \& Maxfield, M.G. (1980). Fear in the neighborhoods: An investigation of the impact of crime. Journal of Research in Crime and Delinquency, 17, 160-189.

McLoyd, V.C. (1998). Socioeconomic disadvantage and child development. American Psychologist, 53, 185-204.

Miles, M.B., \& Huberman, M.A. (1994). An expanded sourcebook: Qualitative data analysis (2nd ed.). Thousand Oaks, CA: Sage.

Neuendorf, K.A. (2002). The content analysis guidebook. Thousand Oaks, CA: Sage.

O'Neil, R., Parke, R.D., \& McDowell, D.J. (2001). Objective and subjective features of children's neighborhoods: Relations to parental regulatory strategies and children's social competence. Applied Developmental Psychology, 22, 135-155.

Pettit, G.S., Bates, J.E., Dodge, K.A., \& Meece, D.W. (1999). The impact of after-school peer contact on early adolescent externalizing problems is moderated by parental monitoring, perceived neighborhood safety, and prior adjustment. Child Development, 70, 768-778.

Pinderhughes, E.E., Nix, R., Foster, E.M., Jones, D., \& the Conduct Problems Prevention Research Group. (2001). Parenting in context: Impact of neighborhood poverty, residential 
stability, public services, social networks, and danger on parental behaviors. Journal of Marriage and Family, 63, 941-953.

Richters, J.E., \& Martinez, P. (1993). The NIMH community violence project, I: Children as victims of and witnesses to violence. Psychiatry, 56, 7-21.

Riger, S., LeBailly, R., \& Gordon, M. (1981). Community ties and urbanites fear of crime: An ecological investigation. American Journal of Community Psychology, 9, 653-665.

Rohe, W.M., \& Burby, R.J. (1988). Fear of crime in public housing. Environment and Behavior, $20,700-720$.

Roosa, M.W., Jones, S., Tein, J.Y., \& Cree, W. (2003). Prevention science and neighborhood influences on low-income children's development: Theoretical and methodological issues. American Journal of Community Psychology, 31, 55-72.

Sampson, R.J., Raudenbush, S.W., \& Earls, F. (1997). Neighborhoods and violent crime: A multilevel study of collective efficacy. Science, 277, 918-924.

Shumow, L., Vandell, D., \& Posner, J. (1998). Perceptions of danger: A psychological mediator of neighborhood demographic characteristics. American Journal of Orthopsychiatry, 68, $468-478$.

Silk, J.S., Sessa, F.M., Morris, A.S., Steinberg, L., \& Avenevoli, S. (2004). Neighborhood cohesion as a buffer against hostile maternal parenting. Journal of Family Psychology, 18, 135-146.

Simons, R.L., Johnson, C., Beaman, J., Conger, R.D., \& Whitbeck, L.B. (1996). Parents and peer group as mediators of the effects of community structure on adolescent problem behavior. American Journal of Community Psychology, 24, 145-171.

U.S. Census Bureau. (2000). Population profile. Income and poverty in 1999. Retrieved March 2008, http://www.census.gov 